\title{
Potential Power of the Pyramidal Structure III: Discovery of Pyramid Effects with and without Seasonal Variation
}

\author{
Osamu Takagii ${ }^{1}$, Masamichi Sakamoto ${ }^{2}$, Hideo Yoichi ${ }^{1}$, Kimiko Kawano $^{1}$, Mikio Yamamoto ${ }^{1}$ \\ ${ }^{1}$ International Research Institute (IRI), Chiba, Japan; ${ }^{2}$ Aquavision Academy, Chiba, Japan \\ Correspondence to: Osamu Takagi, takagi@a-iri.org
}

Keywords: Pyramid, Potential Power, Meditation, Non-Contact Effect, Seasonal Variation, Biosensor, Cucumis sativus, Gas, Psi Index

Received: December 3, $2020 \quad$ Accepted: December 28, $2020 \quad$ Published: December 31, 2020

Copyright $\odot 2020$ by author(s) and Scientific Research Publishing Inc.

This work is licensed under the Creative Commons Attribution International License (CC BY 4.0).

http://creativecommons.org/licenses/by/4.0/

\section{(c) (i) Open Access}

\section{ABSTRACT}

Since October 2007, we have been conducting rigorous scientific research on the unexplained "power" of a pyramidal structure (PS). From our research results so far, we could classify the pyramid effects by the PS into the following two types. (i) The pyramid effects in which the PS converted the test subject's unexplained energy to affect biosensors when the test subject entered the PS and meditated. (ii) The pyramid effects in which the potential power of the PS affected biosensors if the test subject had not been inside the PS for at least 20 days and the test subject's unexplained energy was excluded. In this paper, we report new results regarding (ii). As a result of dividing a year according to the four seasons of winter, spring, summer, and autumn and analyzing the pyramid effect of each period, the following points were found. 1) There was a pyramid effect without seasonal variation. The pyramid effect on the lower and upper layers was different throughout the year for the biosensors placed at the PS apex in two layers, regardless of the season. 2) There was a pyramid effect with seasonal variation. The value of the psi index, which indicates the magnitude of the pyramid effect, changed as the seasons changed, while different pyramid effects were maintained on the lower and upper layers. Regarding the change in the pyramid effect depending on the season, the psi index in summer was larger than that in winter in both the lower and upper layers. From these results, we found that there are two types of potential power at the PS apex: seasonal potential power and non-seasonal potential power.

\section{INTRODUCTION}

From the latter half of the 1930s, attention has been given to the so-called "pyramid power", the effects of a pyramid that cannot be scientifically explained. And to date, many books on pyramid power have been published [1-18]. However, regarding the scientific research of pyramid power, there have been only 
a few papers published in academic journals $[19,20]$ other than the research papers we have published. We have been studying the unexplained "power" of the pyramidal structure (PS) since October 2007. As a result of rigorous scientific experiments and analysis, the existence of an unexplained "power" of the PS, an unexplained "function" of the PS was demonstrated with statistically very high significance. The results of our research on the PS have been published as eight original papers [21-28], three research summaries [29-31], and one chapter in a book [32].

We verified the pyramid effects by analyzing the concentration of gas emitted from biosensors. The method of using cucumber section as biosensors was developed by the International Research Institute (IRI). In addition to detecting the pyramid effects, this method also detected a healer's non-contact effect on the biosensors and a wave like bio-field around the healer [33-35].

From our research results so far, the pyramid effects by the PS can be classified into the following two types. (i) Pyramid effects in which the PS converted the test subject's unexplained energy to affect the biosensors when the test subject entered the PS and meditated, Hemi-Sync ${ }^{\circledast}$ [36]. (ii) Pyramid effects in which the potential power of the PS affected the biosensors if the test subject had not been inside the PS for at least 20 days and the test subject's unexplained energy was excluded. We reported two results on (ii) in previously published papers $[27,28] .1$ ) We demonstrated the pyramid effect that affects the biosensors placed at the PS apex by the potential power of the PS. When the year was divided into two periods, the spring equinox and the autumn equinox, a significant difference was obtained as a result of comparing the pyramid effects of each period, $p=6.0 \times 10^{-3}$, Welch's t-test, two-tails [27] (the following $p$ values are also the Welch's t-test values). 2) We demonstrated that the potential power of the PS affected the biosensors placed in two layers with a difference of $20 \mathrm{~mm}$ in height at the PS apex, and the pyramid effect differed between the lower and the upper layer. The psi index, which indicates the magnitude of the pyramid effect, had a negative value of -3.01 for the lower biosensors, and a positive value of 5.52 for the upper biosensors. There was a significant difference between the lower and upper pyramid effects, $p=4.0 \times 10^{-7}$ [28]. In this paper, regarding (ii), we divide a year into four seasons of winter, spring, summer, and autumn, and report the results of analyzing the pyramid effect of each period.

The purpose of this paper is to demonstrate the coexistence of two types of pyramid effects, the pyramid effect with and without seasonal variation, for the biosensors placed in two layers at the PS apex.

\section{EXPERIMENT}

\subsection{Pyramidal Structure (PS)}

We created the PS shown in Figure 1(a). The PS was a square pyramid with a height of $107 \mathrm{~cm}$, a ridgeline length of $170 \mathrm{~cm}$ and a base length of $188 \mathrm{~cm}$. The tilt angle between the bottom and the side of the PS was $49.1^{\circ}$. The base of the PS was raised to a height of $73 \mathrm{~cm}$ from the floor. The frame of the PS was made of four aluminum pipes, $2 \mathrm{~cm}$ in diameter. On the four sides of the PS there was a Sierpinski triangle pattern and it consisted of aluminum plates. At the PS apex, a Faraday cage for electrostatic shielding of the biosensors was placed. A calibration control point was set up $8 \mathrm{~m}$ away from the PS [21, 32].

\subsection{Detection of the Pyramid Effects}

In order to clarify the presence of the "pyramid power" in the PS, we verified the pyramid effect on the biosensors (cucumber fruit sections). In general, injuries to living bodies such as plants are known to cause biological protection and repair reactions [37-40]. Regarding these reactions, we noticed that there was a variable gas concentration from a gas generation reaction on the cut section (an injury) of the cucumbers. Then we measured the concentration of gas released from the biosensors, cucumber fruit section Cucumis sativus "white spine type", to detect the pyramid effects, that is, the pyramid power of the PS. In order to prepare uniform biosensors, we used the simultaneous calibration technique (SCAT) (Figure 1(b)) [41].

In Figure 1(b), $G_{\mathrm{E}}$ indicated an experimental sample and $G_{\mathrm{C}}$, a control sample. The $G_{\mathrm{E}}$ and $G_{\mathrm{C}}$ of a pair had the same section, but the directions of the axes were different. The direction of the upper surface 


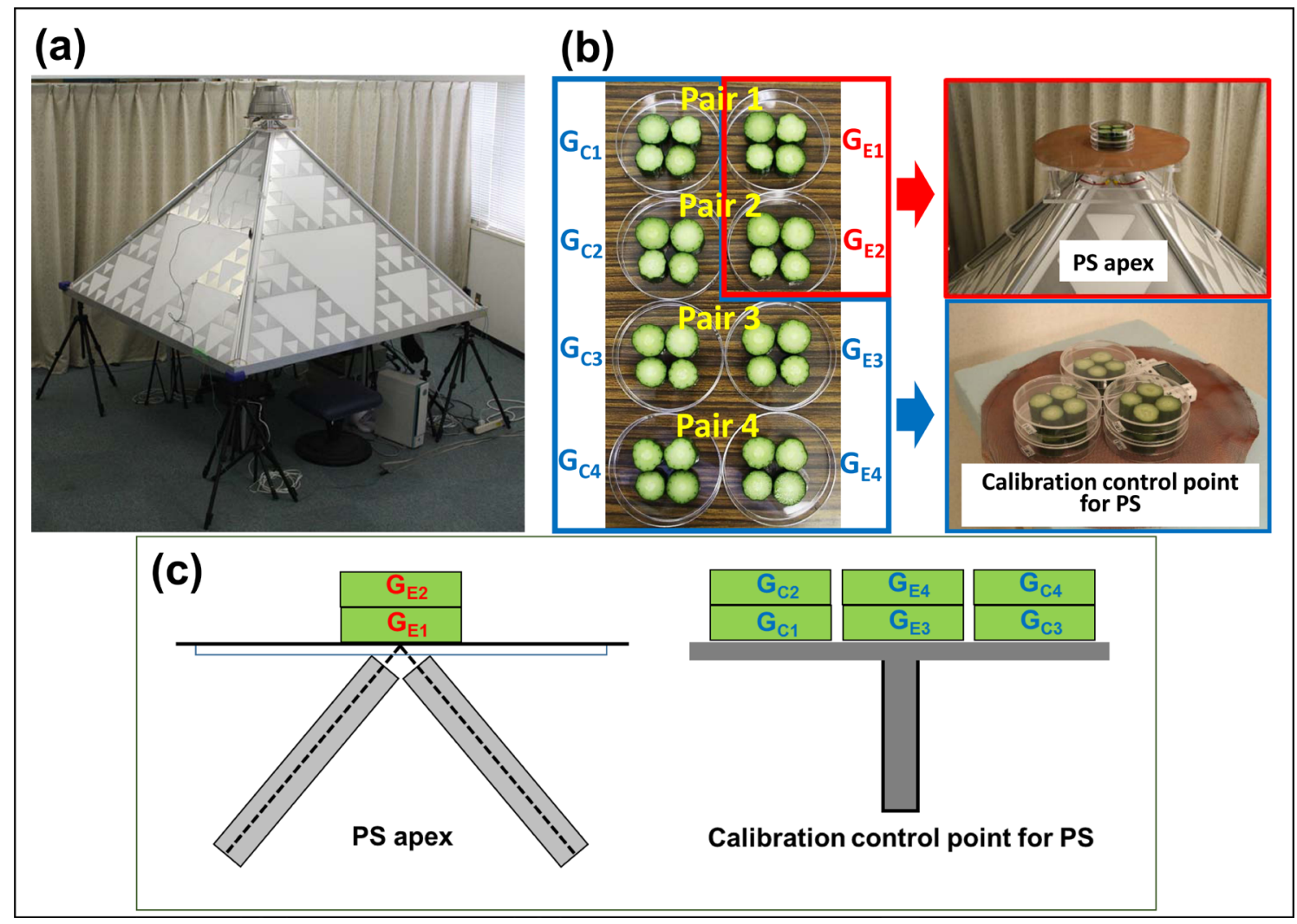

Figure 1. Pyramidal structure, biosensors and installation status as used in the experiment. (a) The pyramidal structure (PS) used in the experiment. (b) Left, biosensors prepared according to SCAT; right, placement of samples on the PS apex and calibration control point for the PS. (c) Placement of samples at the PS apex and calibration control point, and the arrangement diagram.

of the cucumber section placed on the Petri dish was defined as the direction from the lower surface in contact with the Petri dish to the upper surface. At this time, the section on the upper surface of the $G_{\mathrm{E}}$ was in the same direction as the growth axis of the cucumber, and the section on the upper surface of the $G_{\mathrm{C}}$ was in the opposite direction to the growth axis of the cucumber. Here, the growth axis of cucumber was the direction from the vine side to the flower side of the cucumber fruit. The gas concentration depends on the direction of the section, and we have demonstrated that $G_{\mathrm{E}}<G_{\mathrm{C}}$ [25]. $G_{\mathrm{E} 1}$ and $G_{\mathrm{E} 2}$ were placed at the PS apex in two layers, and $G_{\mathrm{C} 1}, G_{\mathrm{C} 2}, G_{\mathrm{E} 3}, G_{\mathrm{E} 4}, G_{\mathrm{C} 3}$ and $G_{\mathrm{C} 4}$ were placed on the calibration control point $8 \mathrm{~m}$ away from the PS in two layers. The difference in height between the two layers was $20 \mathrm{~mm}$. The larger subscript number was the upper layer, and the lower layer was Layer 1, and the upper layer was Layer 2. The center point of the bottom of the Petri dish of $G_{\text {E1 }}$ placed at the PS apex coincided with the extension of the center of the four aluminum pipes near the PS apex (Figure 1(c), Figure 2(a), Figure 2(b)). The setting time of the biosensors was 30 minutes. After setting for $30 \mathrm{~min}$, the lid of the Petri dish was removed, and the Petri dishes were placed one by one in a closed container with a volume of 2.2 liters, and the closed containers were stored side by side for each pair. Storage time was $24 \mathrm{~h}-48 \mathrm{~h}$. After storage, the gas concentrations released from the cucumber sections were measured. Gas detection tubes (Ethyl acetate detector tube $141 \mathrm{~L}$ : Gastech, Japan) and a gas sampling pump (GV-100: Gastech, Japan) were used to measure the gas concentrations.

\subsection{Indicator of the Magnitude of the Pyramid Effects: Psi Index $\Psi$}

We expressed the pyramid effects on the biosensors by the psi index $\Psi[27,28,32] . \Psi$ was 100 times 


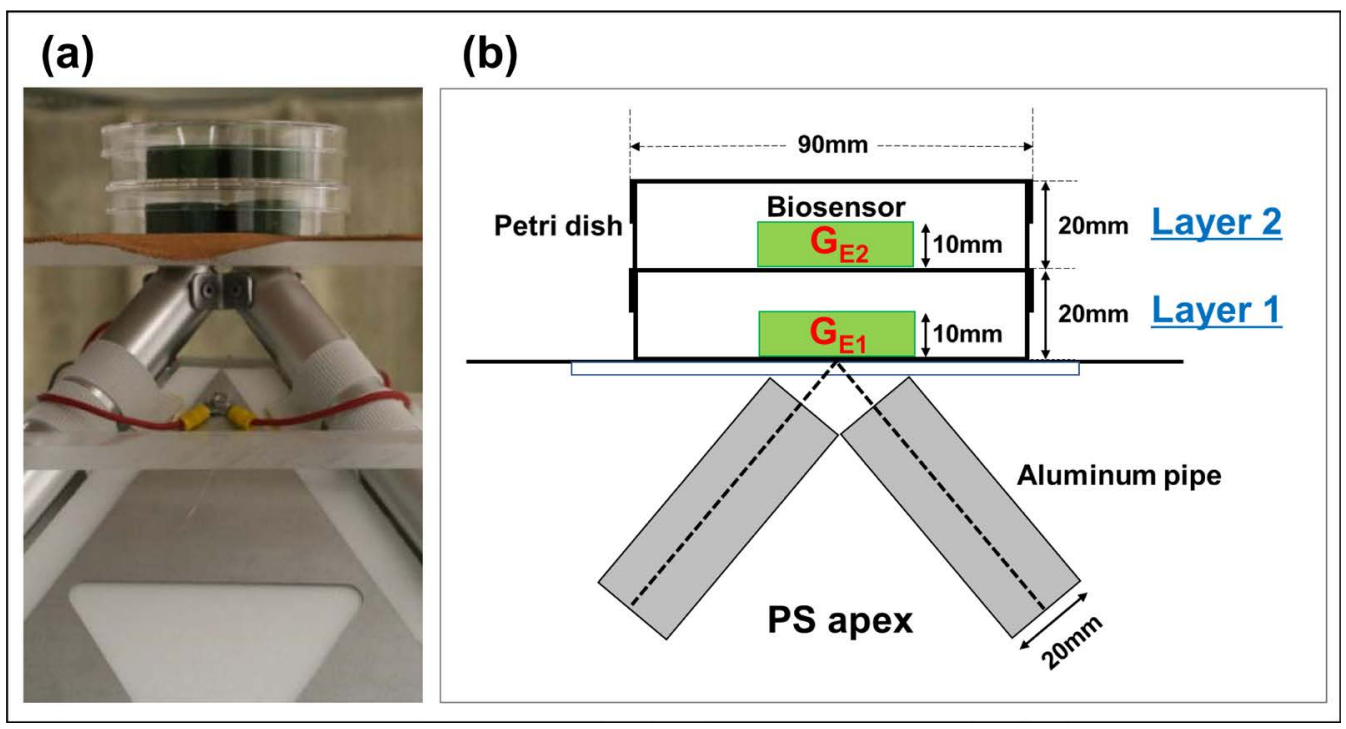

Figure 2. Biosensors placed in two layers at the PS apex. (a) Photo. (b) Arrangement diagram.

the natural logarithm of the ratio calculated for the gas concentrations of each pair. The relationship between the $J$ value we used previously and $\Psi$ was $\Psi=100 J[42]$.

$$
\begin{aligned}
& \Psi_{1}=100 \ln \left(G_{\mathrm{E} 1} / G_{\mathrm{C} 1}\right), \\
& \Psi_{2}=100 \ln \left(G_{\mathrm{E} 2} / G_{\mathrm{C} 2}\right), \\
& \Psi_{3}=100 \ln \left(G_{\mathrm{E} 3} / G_{\mathrm{C} 3}\right), \\
& \Psi_{4}=100 \ln \left(G_{\mathrm{E} 4} / G_{\mathrm{C} 4}\right) .
\end{aligned}
$$

In Equations (1), $G_{\mathrm{E} 1}-G_{\mathrm{E} 4}$ and $G_{\mathrm{C} 1}-G_{\mathrm{C} 4}$ were gas concentrations (ppm) measured from the biosensors. $\Psi_{1}-\Psi_{4}$ were the psi indices before calibration.

$$
\begin{aligned}
& \Psi_{1(\text { E-CAL })}=\Psi_{1}-\left(\Psi_{3}+\Psi_{4}\right) / 2, \\
& \Psi_{2(\text { E-CAL })}=\Psi_{2}-\left(\Psi_{3}+\Psi_{4}\right) / 2, \\
& \Psi_{3(\text { C-CAL })}=\Psi_{3}-\left(\Psi_{3}+\Psi_{4}\right) / 2, \\
& \Psi_{4(\text { C-CAL })}=\Psi_{4}-\left(\Psi_{3}+\Psi_{4}\right) / 2 .
\end{aligned}
$$

$\Psi_{1(\mathrm{E}-\mathrm{CAL})}$ and $\Psi_{2(\mathrm{E}-\mathrm{CAL})}$ in Equations (2) are the results of calibration for environmental factors such as temperature, humidity, atmospheric pressure, geomagnetism, etc., and they are also calibrated for the cutting direction. The absolute values of $\Psi_{1(\mathrm{E}-\mathrm{CAL})}$ and $\Psi_{2(\mathrm{E}-\mathrm{CAL})}$, which are calibrated psi indices, represent the magnitude of the pyramid effects. The average of the pyramid effects on the biosensors placed in two layers at the PS apex is calculated by Equation (3).

$$
\Psi_{(\mathrm{E}-\mathrm{CAL})}=\left(\Psi_{1(\mathrm{E}-\mathrm{CAL})}+\Psi_{2(\mathrm{E}-\mathrm{CAL})}\right) / 2 .
$$

When determining the pyramid effect on the lower and upper layers of the biosensors placed at the PS apex in two layers, it is necessary to calibrate the difference between the upper and lower layers when stacked in two layers. Therefore, the pyramid effects on the lower (Layer 1) and upper (Layer 2) biosensors are calculated by Equation (4).

$$
\begin{aligned}
& \Psi_{1(\mathrm{E}-\mathrm{CAL}) \mathrm{Layer} 1}=\Psi_{1(\mathrm{E}-\mathrm{CAL})}-\Psi_{3(\mathrm{C}-\mathrm{CAL})}=\Psi_{1}-\Psi_{3}, \\
& \Psi_{2(\mathrm{E}-\mathrm{CAL}) \mathrm{Layer} 2}=\Psi_{2(\mathrm{E}-\mathrm{CAL})}-\Psi_{4(\mathrm{C}-\mathrm{CAL})}=\Psi_{2}-\Psi_{4} .
\end{aligned}
$$




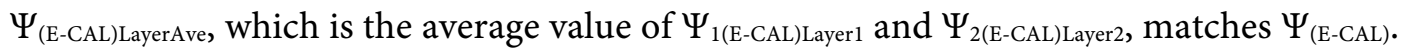

$$
\begin{aligned}
\Psi_{(\mathrm{E}-\mathrm{CAL}) \text { LayerAve }} & =\left(\Psi_{1(\mathrm{E}-\mathrm{CAL}) \mathrm{Layer} 1}+\Psi_{2(\mathrm{E}-\mathrm{CAL}) \mathrm{Layer} 2}\right) / 2 \\
& =\left(\Psi_{1(\mathrm{E}-\mathrm{CAL})}+\Psi_{2(\mathrm{E}-\mathrm{CAL})}\right) / 2 \\
& =\Psi_{(\mathrm{E}-\mathrm{CAL})} .
\end{aligned}
$$

\section{EXPERIMENTAL RESULTS AND ANALYSIS}

Figure 3(a) shows the distribution of $\Psi_{\text {(E-CAL)LayerAve. The total number of data was } n=468 \text {, which were }}$ results of experiments conducted between July 2010 and September 2017 [27, 28]. The horizontal axis is the number of days $(1-366)$ counted from January 1st of each year. Figure 3(b) shows the average value of $\Psi_{\text {(E-CAL)LayerAve. }}$ From this graph, the average value of the pyramid effects on the biosensors placed in two layers at the PS apex was zero within the margin of error. The error bar shows the $99 \%$ confidence interval. We have already demonstrated that the pyramid effects on the biosensors placed in two layers at the PS apex differed between the lower and upper layers [28]. Therefore, we next analyzed the pyramid effects on the lower and upper biosensors, $\Psi_{1(\mathrm{E}-\mathrm{CAL}) \mathrm{Layer} 1}$ and $\Psi_{2(\mathrm{E}-\mathrm{CAL}) \mathrm{Layer} 2}$.

Figure 4(a) shows the distribution of the $\Psi_{1(\mathrm{E}-\mathrm{CAL}) \mathrm{Layer} 1}$ and the $\Psi_{2(\mathrm{E}-\mathrm{CAL}) \text { Layer2 }}$ of the biosensors placed in two layers at the PS apex. The horizontal axis is the number of days counted from January 1st, as in Figure 3(a). Figure $4(\mathrm{~b})$ shows the average values of $\Psi_{1(\mathrm{E}-\mathrm{CAL}) \text { Layer1 }}$ and $\Psi_{\text {2(E-CAL)Layer2. The }} \Psi_{1(\mathrm{E}-\mathrm{CAL}) \text { Layer1 }}$ average was -3.01 , and it had $1 \%$ statistical significance on the negative side. The $\Psi_{2(\mathrm{E}-\mathrm{CAL}) \mathrm{Layer} 2}$ average was 5.52 , and it had $1 \%$ statistical significance on the positive side. The p-value between $\Psi_{1(\mathrm{E}-\mathrm{CAL}) \text { Layer } 1}$ and $\Psi_{2(\mathrm{E}-\mathrm{CAL}) \text { Layer2 } 2 \text { was }} p$ $=4.0 \times 10^{-7}$. As a result of analyzing the lower and upper layers separately for the biosensors placed at the PS apex in two layers, the pyramid effects could be detected with statical significance. Moreover, we obtained the result that the signs were different between $\Psi_{1(\mathrm{E}-\mathrm{CAL}) \text { Layer1 }}$ and $\Psi_{\text {2(E-CAL)Layer2. The error bar shows }}$ the $99 \%$ confidence interval.

In Figure 5, the horizontal axis is divided into four periods (I)-(IV) for the distribution of $\Psi_{1(\mathrm{E}-\mathrm{CAL}) \text { Layer } 1}$ and $\Psi_{2(\mathrm{E}-\mathrm{CAL}) \text { Layer } 2}$ in Figure $4(\mathrm{a})$. (I) is the "winter" period from the winter solstice to the day before the spring equinox (12/22 - 3/20), (II) is the "spring" period from the spring equinox to the day before the summer solstice $(3 / 21-6 / 20)$, (III) is the "summer" period from the summer solstice to the day before the autumn equinox $(6 / 21-9 / 22)$, and (IV) is the "autumn" period from the autumn equinox to the
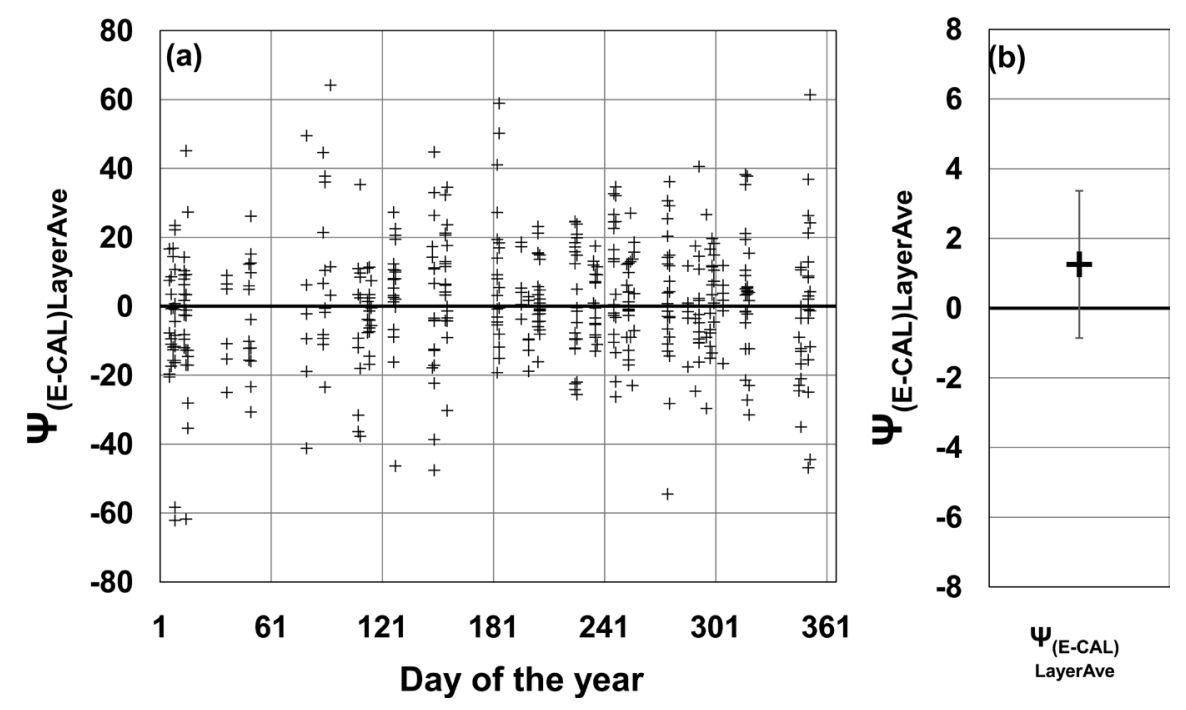

Figure 3. The psi index $\Psi_{(\mathrm{E}-\mathrm{CAL}) \mathrm{LayerAve}}$. (a) Distribution of $\Psi_{(\mathrm{E}-\mathrm{CAL}) \mathrm{LayerAve}}$ (b) Average value of $\Psi$ (E-CAL)LayerAve. 

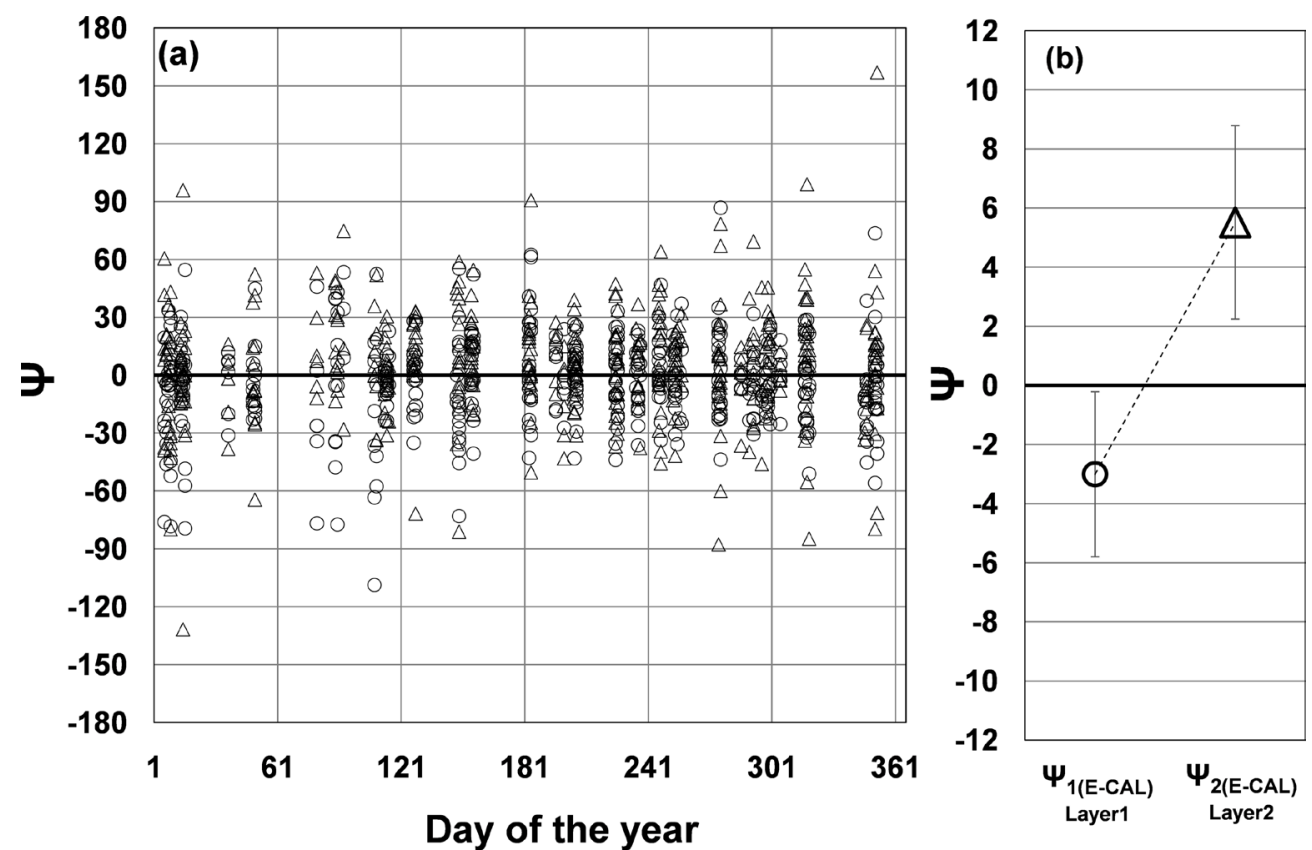

Figure 4. Psi index $\Psi_{1(\mathrm{E}-\mathrm{CAL}) \mathrm{Layer} 1}$ and $\Psi_{2(\mathrm{E}-\mathrm{CAL}) \mathrm{Layer2} 2}$ (a) Distribution of $\Psi_{1(\mathrm{E}-\mathrm{CAL}) \mathrm{Layer} 1}$ and $\Psi_{2(\mathrm{E}-\mathrm{CAL}) \mathrm{Layer} 2}$. Circle: $\Psi_{1(\mathrm{E}-\mathrm{CAL}) \mathrm{Layer} 1}$, Triangle: $\Psi_{2(\mathrm{E}-\mathrm{CAL}) \mathrm{Layer} 2}$. (b) The individual averages of $\Psi_{1(\mathrm{E}-\mathrm{CAL}) \mathrm{Layer} 1}$ and $\Psi_{2(\mathrm{E}-\mathrm{CAL}) \mathrm{Layer2} \text {. }}$

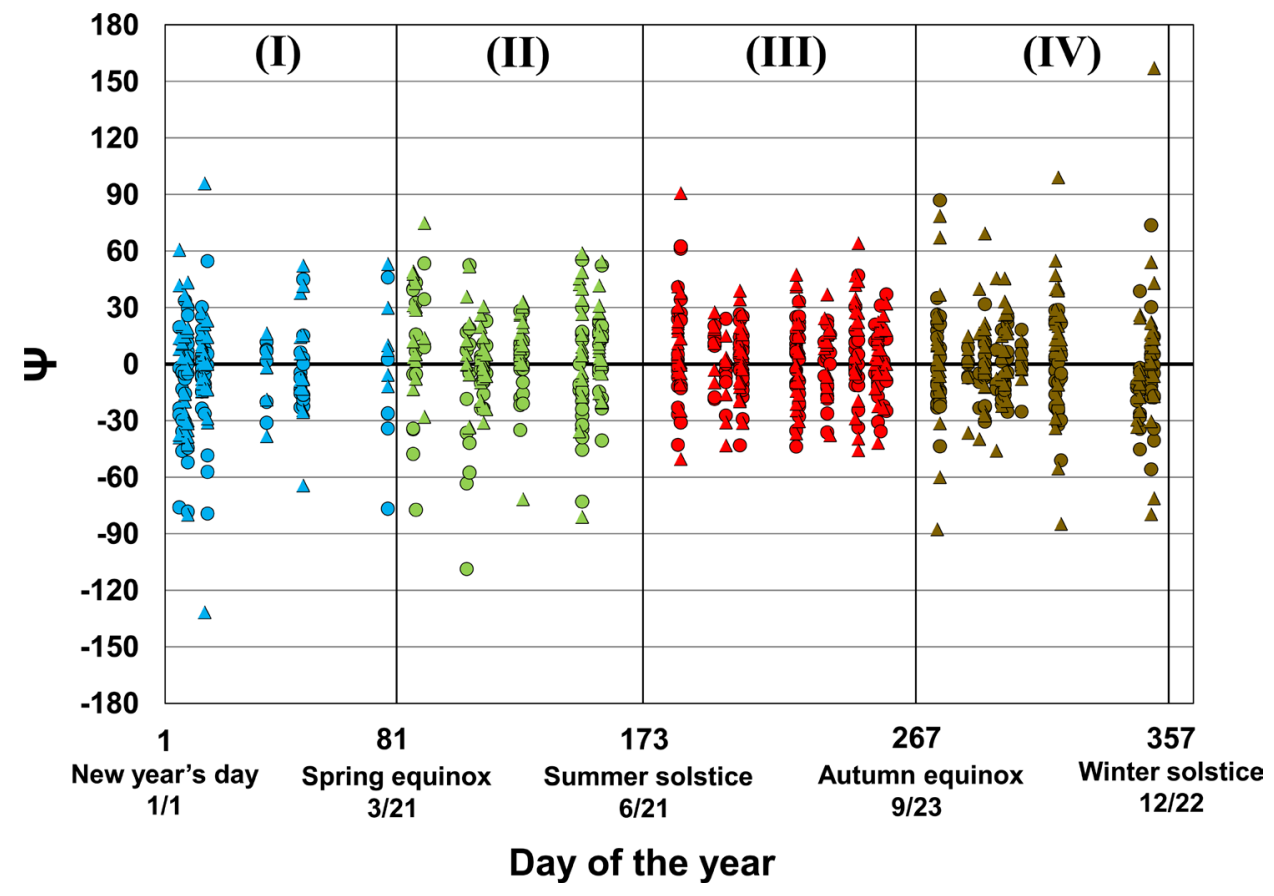

Figure 5. The results of dividing the horizontal axis of Figure 4(a) into four periods (I)-(IV). (I) is the "winter" period from the winter solstice to the day before the spring equinox $(12 / 22-3 / 20)$, (II) is the "spring" period from the spring equinox to the day before the summer solstice $(3 / 21-6 / 20)$, (III) is the "summer" period from the summer solstice to the day before the autumn equinox (6/21 9/22), and (IV) is the "autumn" period from the autumn equinox to the day before the winter solstice $\left(9 / 23\right.$ - 12/21). Circle: $\Psi_{1(\mathrm{E}-\mathrm{CAL}) \mathrm{Layer} 1}$, Triangle: $\Psi_{2(\mathrm{E}-\mathrm{CAL}) \mathrm{Layer} 2}$. 
day before the winter solstice $(9 / 23$ - 12/21). The data for period (I) are blue $(\mathrm{n}=84)$, the data for period (II) are green $(n=108)$, the data for period (III) are red $(n=144)$, and the data for period (IV) are dark brown $(n=132)$. The solstice and equinox days vary slightly depending on the year, but in this paper, we set the winter solstice as $12 / 22$, the spring equinox as $3 / 21$, the summer solstice as $6 / 21$, and the autumn equinox as $9 / 23$. Figures $6(\mathrm{a})-(\mathrm{d})$ show the averages of $\Psi_{1(\mathrm{E}-\mathrm{CAL}) \text { Layer1 }}$ and $\Psi_{\text {2(E-CAL)Layer2 }}$ in the periods (I)-(IV). In any period of (I)-(IV), $\Psi_{\text {1(E-CAL)Layer1 }}<\Psi_{2(\mathrm{E}-\mathrm{CAL}) \text { Layer2. }}$. We calculated the p-values between $\Psi_{\text {1(E-CAL)Layer1 }}$ and $\Psi_{\text {2(E-CAL)Layer2, }}$ and obtained the following values: (I) $p=7.6 \times 10^{-2}$, (II) $p=1.4 \times 10^{-3}$, (III) $p=2.7 \times 10^{-2}$, and (IV) $p=3.6 \times 10^{-3}$. The p-values of (II) and (IV) had $1 \%$ statistical significance, and (III) had $5 \%$ statistical significance. No significant difference was obtained in (I), probably because the number of data was smaller than in the other periods. We expect that a significant difference can be detected between $\Psi_{1(\mathrm{E}-\mathrm{CAL}) \text { Layer1 }}$ and $\Psi_{2(\mathrm{E}-\mathrm{CAL}) \mathrm{Layer} 2}$ as the number of data increases. The error bar shows the $99 \%$ confidence interval. We also found that the value of the psi index changed while maintaining the state of $\Psi_{1(\mathrm{E}-\mathrm{CAL}) \text { Layer1 }}<\Psi_{2(\mathrm{E}-\mathrm{CAL}) \mathrm{Layer} 2}$ in each period of Figures $6(\mathrm{a})-(\mathrm{d})$. In particular, both $\Psi_{1(\mathrm{E}-\mathrm{CAL}) \mathrm{Layer} 1}$ and $\Psi_{2(\mathrm{E}-\mathrm{CAL}) \text { Layer2 }}$ were negative values in (I), but they were positive values in (III). From this, we clarified that there is a pyramid effect indicating seasonal variation, and the pyramid effect is qualitatively reversed in "summer" and "winter".

Figure 7 (a) shows the changes for $\Psi_{1(\mathrm{E}-\mathrm{CAL}) \mathrm{Layer} 1}$ and $\Psi_{\text {2(E-CAL)Layer2 }}$ during the periods (I)-(IV). In (I), $\Psi_{1(\mathrm{E}-\mathrm{CAL}) \mathrm{Layer} 1}$ and $\Psi_{2(\mathrm{E}-\mathrm{CAL}) \mathrm{Layer} 2}$ showed the minimum values. However, the period showing the maximum value was (II) in the case of $\Psi_{1(\mathrm{E}-\mathrm{CAL}) \mathrm{Layer} 1}$ and (III) in the case of $\Psi_{2(\mathrm{E}-\mathrm{CAL}) \mathrm{Layer} 2}$, and the periods were shifted. Figure $7(\mathrm{~b})$ shows the seasonal change of the average values $\Psi_{(\mathrm{E}-\mathrm{CAL}) \text { LayerAve }}$ of $\Psi_{1(\mathrm{E}-\mathrm{CAL}) \text { Layer1 }}$ and $\Psi_{2(\mathrm{E}-\mathrm{CAL}) \text { Layer2 }}$ in the periods (I)-(IV). The p-value of $\Psi_{(\mathrm{E}-\mathrm{CAL}) \text { LayerAve }}$ in (I) and (III) was $1.8 \times 10^{-3}$. The error bar shows the $99 \%$ confidence interval.
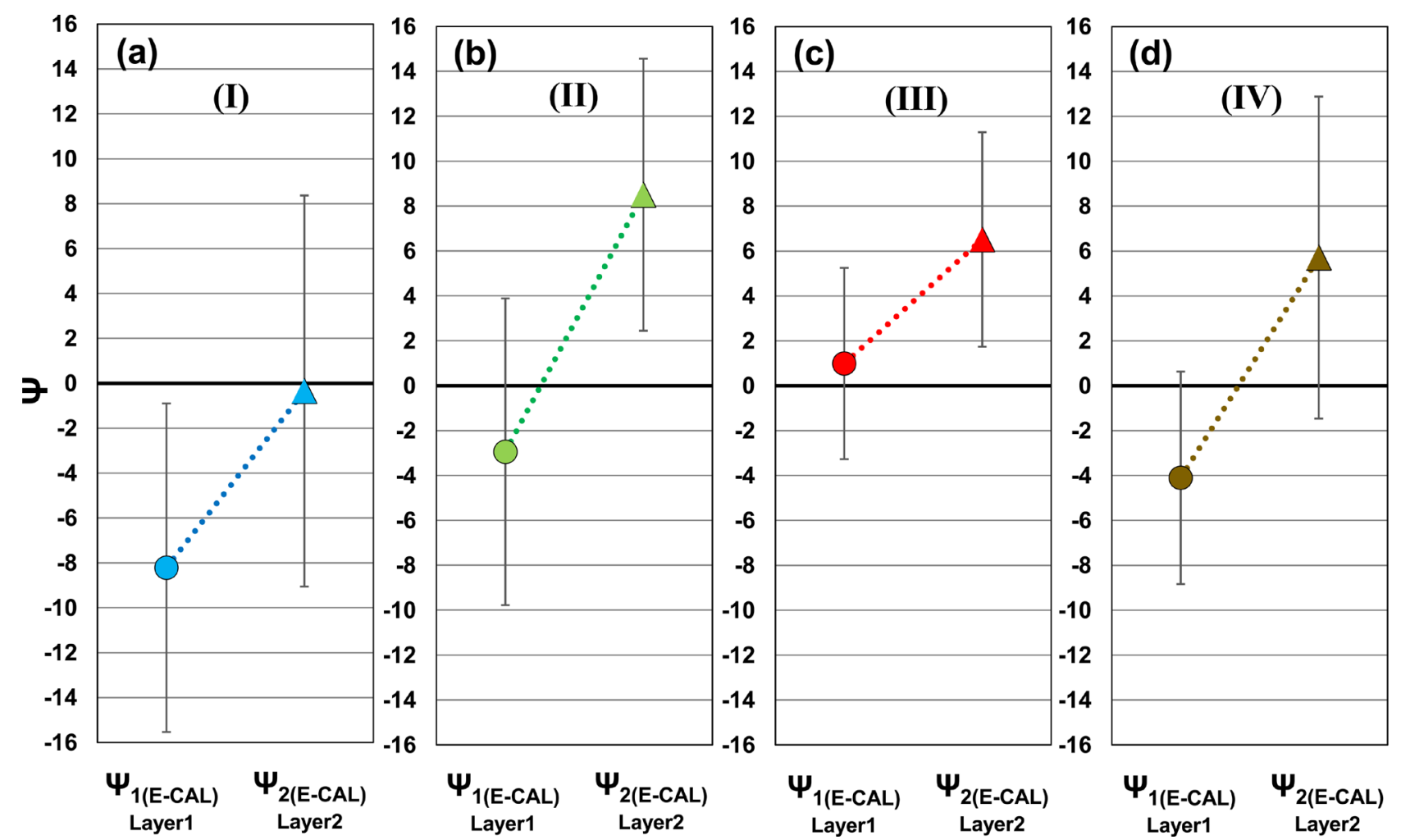

Figure 6. (a)-(d) Averages of $\Psi_{1(\mathrm{E}-\mathrm{CAL}) \text { Layer1 }}$ and $\Psi_{2(\mathrm{~B}-\mathrm{CAL}) \mathrm{Layer21}}$ and averages in the periods (I)-(IV). The $p$-values between $\Psi_{1(\mathrm{E}-\mathrm{CAL}) \text { Layer } 1}$ and $\Psi_{2(\mathrm{E}-\mathrm{CAL}) \text { Layer } 2}$ for the periods were: (I) $p=7.6 \times 10^{-2}$, (II) $p=1.4 \times$ $10^{-3}$, (III) $p=2.7 \times 10^{-2}$, and (IV) $p=3.6 \times 10^{-3}$. Circle: $\Psi_{1(\mathrm{E}-\mathrm{CAL}) \mathrm{Layer} 1}$, Triangle: $\Psi_{2(\mathrm{E}-\mathrm{CAL}) \mathrm{Layer} 2}$. 


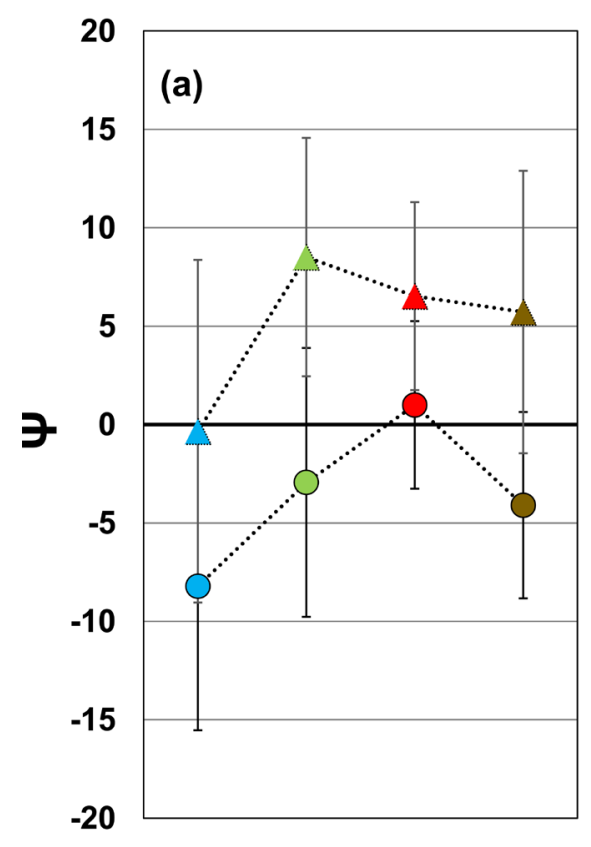

(I) (II) (III) (IV)

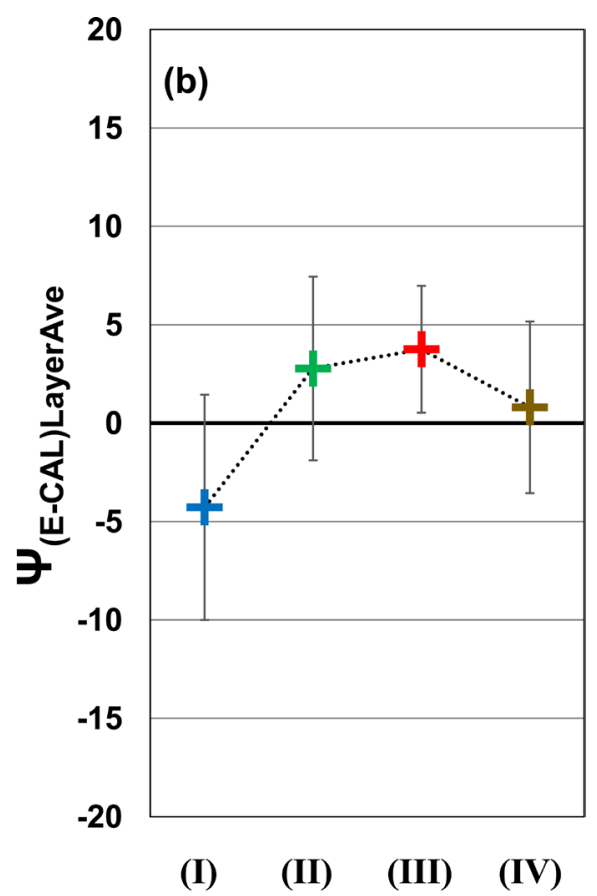

Figure 7. (a) Changes in $\Psi_{1(\mathrm{E}-\mathrm{CAL}) \mathrm{Layer} 1}$ and $\Psi_{2(\mathrm{E}-\mathrm{CAL}) \mathrm{Layer} 2}$ during periods (I)-(IV). Circle: $\Psi_{1(\mathrm{E}-\mathrm{CAL}) \mathrm{Layer} 1}$, Triangle: $\Psi_{2(\mathrm{E}-\mathrm{CAL}) \mathrm{Layer} 2}$ (b) Changes in the average $\Psi_{(\mathrm{E}-\mathrm{CAL}) \mathrm{LayerAve}}$ of $\Psi_{1(\mathrm{E}-\mathrm{CAL}) \mathrm{Layer} 1}$ and $\Psi_{2(\mathrm{E}-\mathrm{CAL}) \mathrm{Layer} 2}$ during periods (I)-(IV).
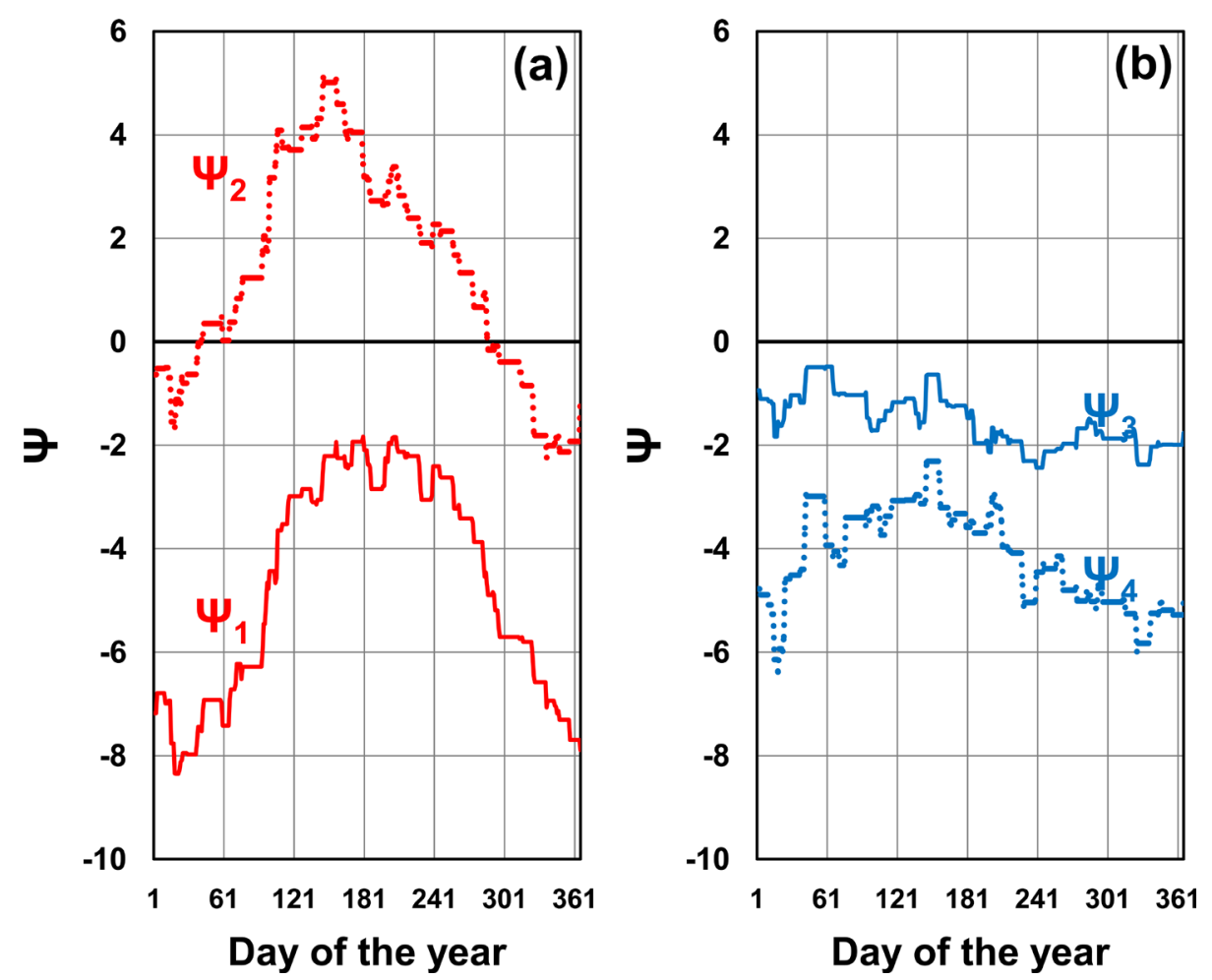

Figure 8. Moving average of psi indices $\Psi_{1}-\Psi_{4}$. (a) and (b) are moving averages of the psi indices $\Psi_{1}$ - $\Psi_{4}$, window size is 180 days. The solid line is the psi index calculated from the lower layer pair, and the dotted line is the psi index calculated from the upper layer pair. 


\section{DISCUSSION}

The result that there are two types of pyramid effects for the biosensors placed at the PS apex can be qualitatively understood from the results of the moving averages of $\Psi_{1}-\Psi_{4}$ shown in Figure 8 [28]. For $\Psi_{1}$ and $\Psi_{2}, \Psi_{1}<\Psi_{2}$ throughout the year, and both $\Psi_{1}$ and $\Psi_{2}$ have larger psi index values in summer than in winter. On the other hand, $\Psi_{3}$ and $\Psi_{4}$ are $\Psi_{3}>\Psi_{4}$ throughout the year, but the values of the psi index in winter and summer are not so different. From this, when considering the lower and upper psi indices, $\Psi_{1(\mathrm{E}-\mathrm{CAL}) \mathrm{Layer} 1}=\Psi_{1}-\Psi_{3}$ and $\Psi_{2(\mathrm{E}-\mathrm{CAL}) \mathrm{Layer} 2}=\Psi_{2}-\Psi_{4}$, the relationship of $\Psi_{1(\mathrm{E}-\mathrm{CAL}) \mathrm{Layer} 1}<\Psi_{2(\mathrm{E}-\mathrm{CAL}) \mathrm{Layer} 2}$ can be obtained throughout the year. It can also be understood that both $\Psi_{\text {1(E-CAL)Layer1 }}$ and $\Psi_{\text {2(E-CAL)Layer2 }}$ have a larger psi index in summer than in winter. In addition, the characteristics of the pyramid effects on the biosensors due to the two types of potential power of the PS can be theoretically explained by the model we proposed in our previous papers $[27,28]$.

\section{CONCLUSIONS}

In this paper, we analyzed the pyramid effects on biosensors by the potential power of the PS when the effect of the test subject on the PS was excluded. As a result of analyzing the pyramid effects of each period by dividing the year into four seasons of winter, spring, summer, and autumn, the following points were found. 1) The existence of the pyramid effect without seasonal variation: For the biosensors placed in two layers with a height difference of $20 \mathrm{~mm}$ on the PS apex, the pyramid effects on the lower and upper layers differed throughout the year regardless of the season, and the lower layer psi index was smaller than the upper layer psi index. It became clear that $\Psi_{\text {1(E-CAL)Layer1 }}<\Psi_{2(\mathrm{E}-\mathrm{CAL}) \text { Layer2. }}$ 2) The existence of the pyramid effect with seasonal variation: We clarified that the value of the psi index changed as the seasons changed, while maintaining the condition that $\Psi_{1(\mathrm{E}-\mathrm{CAL}) \mathrm{Layer} 1}<\Psi_{2(\mathrm{E}-\mathrm{CAL}) \mathrm{Layer} 2}$ where the pyramid effects on the lower and upper layers were different. As for seasonal changes, the psi index in summer was larger than that in winter in both the lower and upper layers. From these results, we found that at the PS apex, there were two types of potential power: seasonally variable potential power and the non-seasonally variable potential power.

Prior to our reports, there were few reliable academic studies and statistically significant data on so-called "pyramid power". Since 2007, we have been conducting rigorous scientific experiments and analyses using biosensors to elucidate the unexplained "power" of the PS. As a result, we demonstrated the existence of "pyramid power", which was often recognized as having no scientific basis, with high statistical accuracy. While research on pyramid power is still often regarded as heretical in academia, our extremely high statistical accuracy experimental results are the world's first scientific research results in this field. In the future, these results will surely be widely recognized and will become the basis for a new research field. Furthermore, we expect that pyramid power will have a wide range of applications.

\section{CONFLICTS OF INTEREST}

The authors declare no conflicts of interest regarding the publication of this paper.

\section{REFERENCES}

1. Ostrander, S. and Schroeder, L. (1970) Psychic Discoveries Behind the Iron Curtain. Prentice-Hall, Inc., Upper Saddle River.

2. Flanagan, P. (1973) Pyramid Power: The Science of the Cosmos. PhiSciences Press, Cottonwood.

3. Flanagan, P. (1973) Pyramid Power: The Millennium Science. Earthpulse Press, Inc., Anchorage.

4. Flanagan, P. (1981) Pyramid Power II: The Scientific Evidence. Innergy Publications, Tucson.

5. Toth, M. and Nielsen, G. (1974) Pyramid Power. Destiny Books, Rochester.

6. Schul, B. and Pettit, E. (1975) The Secret Power of Pyramids. Fawcett Gold Medal, New York. 
7. Wyckoff, J. (1976) Using Pyramid Power. Kensington Publishing Corp., New York.

8. Stark, N. (1977) The First Practical Pyramid Book: Free Energy for Beauty, Health, Gardening, Food Dehydration, and Meditation. Sheed Andrews and McMeel, Inc., Kansas City.

9. King, S. (1977) Pyramid Energy Handbook. Warner Books, New York.

10. Gray, C.G. and Gray, V. (1979) Secrets from Beyond the Pyramids. The Alternative Universe Edmonton, Alberta.

11. Schul, B. and Pettit, E. (1979) Pyramid Power a New Reality. Stillpoint, Walpole.

12. Dunn, C. (1998) The Giza Power Plant: Technologies of Ancient Egypt. Bear \& Company, Rochester.

13. Childress, D.H. (2000) Technology of the Gods: The Incredible Sciences of the Ancients. Adventures Unlimited Press, Kempton.

14. Elfouly, G. (2012) The Great Pyramid System: The Blue Light. An Amazon Company, North Charleston.

15. Creighton, S. and Osborn, G. (2012) The Giza Prophecy. Bear \& Company, Rochester.

16. Kiss, Z.J. (2015) The Quantum Impulse and the Space-Time Matrix: The Power of the Hydrogen Process and the Pyramid. Trafford Publishing, Bloomington.

17. Lyke, S. (2018) The Great Pyramid's Laser Power Plant.

18. Brown, J.E., Hurtak, J.J. and Hurtak, D. (2019) Giza's Industrial Complex: Ancient Egypt's Electrical Power and Gas Generating Systems. Academy for Future Science, Los Gatos.

19. Rubik, B. (2016) Interactions of Pyramidal Structures with Energy and Consciousness. The Journal of Natural and Social Philosophy, 12, 259-275. https://www.researchgate.net/publication/309407219

20. Grandics, P. (2009) The Pyramid Electric Generator. Infinite Energy, No. 84, 1-4. https://www.researchgate.net/publication/255709759

21. Takagi, O., Sakamoto, M., Kokubo, H., Yoichi, H., Kawano, K. and Yamamoto, M. (2013) Meditator's Non-Contact Effect on Cucumbers. International Journal of Physical Sciences, 8, 647-651. https://doi.org/10.5897/IJPS2012.3800

22. Takagi, O., Sakamoto, M., Yoichi, H., Kokubo, H., Kawano, K. and Yamamoto, M. (2015) Discovery of an Anomalous Non-Contact Effect with a Pyramidal Structure. International Journal of Sciences, 4, 42-51. https://doi.org/10.18483/ijSci.714

23. Takagi, O., Sakamoto, M., Yoichi, H., Kokubo, H., Kawano, K. and Yamamoto, M. (2016) An Unknown Force Awakened by a Pyramidal Structure. International Journal of Sciences, 5, 45-56. https://doi.org/10.18483/ijSci.1038

24. Takagi, O., Sakamoto, M., Yoichi, H., Kokubo, H., Kawano, K. and Yamamoto, M. (2018) Discovery of Seasonal Dependence of Bio-Reaction Rhythm with Cucumbers. International Journal of Science and Research Methodology, 9, 163-175. https://www.researchgate.net/publication/331917254

25. Takagi, O., Sakamoto, M., Yoichi, H., Kokubo, H., Kawano, K. and Yamamoto, M. (2018) Relationship between Gas Concentration Emitted from Cut Cucumber Cross Sections and Growth Axis. International Journal of Science and Research Methodology, 9, 153-167. https://www.researchgate.net/publication/331917255

26. Takagi, O., Sakamoto, M., Yoichi, H., Kokubo, H., Kawano, K. and Yamamoto, M. (2019) Discovery of an Unexplained Long-Distance Effect Caused by the Association between a Pyramidal Structure and Human Unconsciousness. Journal of International Society of Life Information Science, 37, 4-16.

27. Takagi, O., Sakamoto, M., Yoichi, H., Kawano, K. and Yamamoto, M. (2019) Potential Power of the Pyramidal Structure. Natural Science, 11, 257-266. https://doi.org/10.4236/ns.2019.118026

28. Takagi, O., Sakamoto, M., Yoichi, H., Kawano, K. and Yamamoto, M. (2020) Potential Power of the Pyramidal 
Structure II. Natural Science, 12, 248-272. https://doi.org/10.4236/ns.2020.125022

29. Takagi, O., Sakamoto, M., Yoichi, H., Kokubo, H., Kawano, K. and Yamamoto, M. (2016) Necessary Condition of an Anomalous Phenomenon Discovered by a Pyramidal Structure. Journal of International Society of Life Information Science, 34, 154-157.

30. Takagi, O., Sakamoto, M., Yoichi, H., Kokubo, H., Kawano, K. and Yamamoto, M. (2019) Discovery from the Experiment on the Unexplained Functions of the Pyramidal Structure-The Phenomenon Caused by the Personal Relationship. Journal of International Society of Life Information Science, 37, 60-65.

31. Takagi, O., Sakamoto, M., Yoichi, H., Kawano, K. and Yamamoto, M. (2020) Scientific Elucidation of Pyramid Power: I. Journal of International Society of Life Information Science, 38, 130-145. https://www.researchgate.net/publication/344603987_Scientific_Elucidation_of_Pyramid_Power_I

32. Takagi, O., Sakamoto, M., Yoichi, H., Kawano, K. and Yamamoto, M. (2020) Meditator's Non-Contact Effect on Cucumbers. In: Rafatullah, M., Ed., Theory and Applications of Physical Science, Vol. 3, Book Publisher International, London, Chapter 4.

33. Kokubo, H. and Yamamoto, M. (2009) Controlled Healing Power and Ways of Non-Contact Healing. Journal of International Society of Life Information Science, 27, 90-105.

34. Kokubo, H., Takagi, O., Koyama, S. and Yamamoto, M. (2011) Discussion of an Approximated Equation for Special Distribution of Controlled Healing Power around a Human Body. Journal of International Society of Life Information Science, 29, 23-34.

35. Kokubo, H. (2015) Ki or Psi-Anomalous Remote Effects of Mind-Body System. Nova Science Publishers, Inc., New York.

36. Atwater, F.H. (1997) Accessing Anomalous States of Consciousness with a Binaural Beat Technology. Journal of Scientific Exploration, 1, 263-274. https://www.allthingspsychic.com/AccessingAnomalousStates.html

37. Farmer, E.E. (2013) Surface-to-Air Signals. Nature, 411, 854-856. https://doi.org/10.1038/35081189

38. Ozawa, R., Arimura, G., Takabayashi, J., Shimoda, T. and Nishioka, T. (2000) Involvement of Jasmonate- and Salicylate-Related Signaling Pathways for the Production of Specific Herbivore-Induced Volatiles in Plants. Plant and Cell Physiology, 41, 391-398. https://doi.org/10.1093/pcp/41.4.391

39. De Moraes, C.M., Lewis, W.J., Paré, P.W., Alborn, H.T. and Tumlinson, J.H. (1998) Herbivore-Infested Plants Selectively Attract Parasitoids. Nature, 393, 570-573. https://doi.org/10.1038/31219

40. De Moraes, C.M., Mescher, M.C. and Tumlinson, J.H. (2001) Caterpillar-Induced Nocturnal Plant Volatiles Repel Conspecific Females. Nature, 410, 577-580. https://doi.org/10.1038/35069058

41. Kokubo, H., Takagi, O. and Koyama, S. (2010) Application of a Gas Measurement Method-Measurement of KI Fields and Non-Contact Healing. Journal of International Society of Life Information Science, 28, 95-103.

42. Kokubo, H., Takagi, O. and Yamamoto, M. (2009) Development of a Gas Measurement Method with Cucumber as a Bio-Sensor. Journal of International Society of Life Information Science, 27, 200-213. 